\title{
Equatorial Pacific peak in biological production regulated by nutrient and upwelling during the late Pliocene/early Pleistocene cooling
}

\author{
J. Etourneau ${ }^{1}$, R. S. Robinson ${ }^{2}$, P. Martinez ${ }^{3}$, and R. Schneider ${ }^{4}$ \\ ${ }^{1}$ Université Pierre et Marie Curie, UMR7159 LOCEAN, 4 Place Jussieu, 75252 Paris, France \\ ${ }^{2}$ Graduate School of Oceanography, University of Rhode Island, Narragansett, RI 02882, USA \\ ${ }^{3}$ Université Bordeaux 1, UMR5805 EPOC, avenue des facultés, 33405 Talence cedex, France \\ ${ }^{4}$ Institut für Geowissenschaften, Christian-Albrechts-Universität Kiel, Ludewig-Meyn-Str. 10, 24118 Kiel, Germany \\ Correspondence to: J. Etourneau (johan.etourneau@locean-ipsl.upmc.fr)
}

Received: 15 February 2013 - Published in Biogeosciences Discuss.: 21 March 2013

Revised: 18 July 2013 - Accepted: 24 July 2013 - Published: 27 August 2013

\begin{abstract}
The largest increase in export production in the eastern Pacific of the last 5.3 Myr (million years) occurred between 2.2 and $1.6 \mathrm{Myr}$, a time of major climatic and oceanographic reorganization in the region. Here, we investigate the causes of this event using reconstructions of export production, nutrient supply and oceanic conditions across the Pliocene-Pleistocene in the eastern equatorial Pacific (EEP) for the last 3.2 Myr. Our results indicate that the export production peak corresponds to a cold interval marked by high nutrient supply relative to consumption, as revealed by the low bulk sedimentary ${ }^{15} \mathrm{~N} /{ }^{14} \mathrm{~N}\left(\delta^{15} \mathrm{~N}\right)$ and alkenone-derived sea surface temperature (SST) values. This $\sim 0.6$ million year long episode of enhanced delivery of nutrients to the surface of the EEP was predominantly initiated through the upwelling of nutrient-enriched water sourced in high latitudes. In addition, this phenomenon was likely promoted by the regional intensification of upwelling in response to the development of intense Walker and Hadley atmospheric circulations. Increased nutrient consumption in the polar oceans and enhanced denitrification in the equatorial regions restrained nutrient supply and availability and terminated the high export production event.
\end{abstract}

\section{Introduction}

The eastern equatorial Pacific (EEP) houses both equatorial and coastal upwelling systems where more than $10 \%$ of global ocean's new biological production is concentrated (Pennington et al., 2006). In the past, upwelling intensity and primary production were found to have evolved in phase with climatic oscillations with increasing local production being attributed to increased nutrient delivery to the surface ocean during the last deglaciation (Martinez and Robinson, 2010; Kienast et al., 2006). Although the causes were likely multiple, all the studies point to the nutrient availability as a regulating factor for biological production (e.g., Dubois et al., 2011; Dubois and Kienast, 2011; Loubere, 2000; Robinson et al., 2009). In contrast, the controls remain poorly known over longer time periods.

In the EEP, the Pliocene/Pleistocene climate transition, which started at $\sim 3.0-2.7 \mathrm{Myr}$, was a period of significant variation in biological production and sea surface temperature (SST) that are largely attributed to high latitude forcing (Bolton et al., 2010; Lawrence et al., 2006). Several mechanisms have been proposed to explain the large and transient increase in export production during the late Pliocene/early Pleistocene cooling, from 2.2 to $1.7 \mathrm{Myr}$, the greatest in amplitude and in time since the early Pliocene, surpassing largely that of the last deglaciation (e.g., Lawrence et al., 2006). It was attributed to the upwelling of cold nutrient-rich waters derived from water masses arising from the Southern Ocean and to a lesser extent from the North Pacific (Bolton 

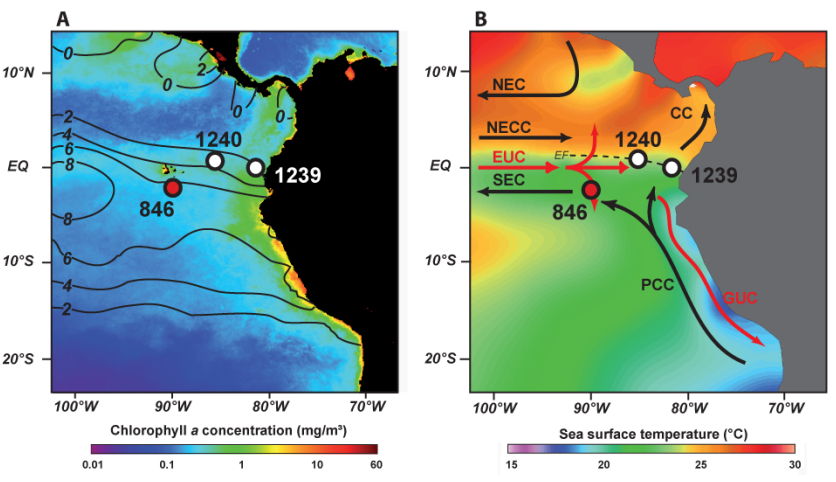

Fig. 1. (A) Production and nutrient distribution in the surface waters of the modern EEP. Colored contours reflect mean annual chlorophyll $a$ concentration (phytoplankton production), and black contoured lines illustrate the mean annual nitrate concentration at $10 \mathrm{~m}$ water depth (Levitus and Boyer, 1994). (B) Surface and subsurface ocean currents in the EEP. Color indicates mean annual sea surface temperature (SST) (Levitus and Boyer, 1994). The study sites from this study are labeled with white dots, Site 1239 and Site 1240, while red dots mark Site 846, where previous alkenone results have been reported (Lawrence et al., 2006). EF: Equatorial Front; EUC: Equatorial Undercurrent; NEC: North Equatorial Current; NECC: North Equatorial Countercurrent; PCC: Peru-Chile Current; SEC: South Equatorial Current.

et al., 2011; Cortese et al., 2004; Lawrence et al., 2006), hypothetically as a result of shoaling of the ventilated thermocline, and possibly of the nutricline, in response to the cooling of the polar oceans (Philander and Fedorov, 2003). The termination of the high productivity period may have resulted from suppressed nutrient supply to the low latitudes in favor of higher productivity in the Antarctic polar frontal zone (Cortese et al., 2004; Etourneau et al., 2012).

However, no evidence for changes in nutrient supply (e.g., nitrate, phosphorus) is available. The inference of strong high latitude forcing during the late Pliocene/early Pleistocene period of high export production is based upon strong power in the $41 \mathrm{kyr}$ spectral band in both SST and paleoproduction data (Lawrence et al., 2006). Here, we investigate the purported changes in nutrient supply to the EEP and their potential relationship to the changes in export production, nitrogen cycling and hydrological reorganization over the last 3.2 Myr. We use $\mathrm{C}_{37}$-alkenone concentration $\left(\mathrm{C}_{37}\right)$, total nitrogen (TN) and organic carbon (TOC) contents with bulk $\delta^{15} \mathrm{~N}$ and alkenone-derived SST from the two well-dated EEP ODP (Ocean Drilling Program) Sites 1239 and 1240.

\section{Regional settings}

Site 1239 is located $120 \mathrm{~km}$ off the Ecuador coast $\left(0^{\circ} 40.32^{\prime} \mathrm{S}, 82^{\circ} 4.86^{\prime} \mathrm{W}\right)$ in $1414 \mathrm{~m}$ of water, and Site 1240 , situated midway between Ecuador and the Galápagos Islands $\left(0^{\circ} 1.31^{\prime} \mathrm{N}, 86^{\circ} 27.76^{\prime} \mathrm{W}\right)$, was cored in $2921 \mathrm{~m}$ water depth
(Fig. 1). The two study sites are located along the edge of the equatorial front (EF) and influenced by the South Equatorial Current (SEC) as the continuation of the Peru-Chile Current (PCC), the North Equatorial Countercurrent (NECC) and the Equatorial Undercurrent (EUC) (Kessler et al., 2006) (Fig. 1). Convergent trade winds from both the Northern Hemisphere and the Southern Hemisphere cause upwelling along the Equator, which is accompanied by the rising of cold water from below the thermocline to the surface, including EUC waters. The nutrient content of the low latitude thermocline is set when mode and intermediate waters sourced in polar regions, from the Southern Ocean and North Pacific (Dugdale et al., 2002), feeding the EUC waters (the primary source of thermocline waters) are formed, placing a fundamental control on EEP primary productivity (Sarmiento et al., 2004). The position of the EF dictates the relative roles of the nutrient-rich EUC and nutrient-poor NECC within the EEP (Toggweiler et al., 1991) and, more specifically, in surface waters overlying Sites 1239 and 1240.

\section{Methods}

Stratigraphy at the EEP Site 1239 between $\sim 3.2$ and $0.5 \mathrm{Myr}$ has been published elsewhere (Etourneau et al., 2010; Steph et al., 2009). It is based on the correlation of the alkenone SSTs between Site 1239 and the well-dated record at Site 846 (Lawrence et al., 2006). In addition, the age model for two specific intervals, $\sim 3.2-2.7$ and $\sim 0.5-0 \mathrm{Ma}$, is based on $\delta^{18} \mathrm{O}$ and $\delta^{13} \mathrm{C}$ measured on benthic Foraminifera (RinconMartinez et al., 2010; Steph et al., 2009) and tuned to the LR04 $\delta^{18} \mathrm{O}$ benthic stack (Lisiecki and Raymo, 2005). Stratigraphy at Site 1240 is also constrained by ${ }^{14} \mathrm{C}$ dating from planktonic foraminifera for the last $40 \mathrm{kyr}$ and tuned to oxygen isotopes with the LR0 $4 \delta^{18} \mathrm{O}$ (Lisiecki and Raymo, 2005 ) between $\sim 2.6-1.8$ and $\sim 0.25-0 \mathrm{Myr}$ (Pena et al., 2008; I. Cacho, personal communication, 2012). Paleomagnetic and biostratigraphic data were used to constrain the intermediate ages (Mix et al., 2003).

$\delta^{15} \mathrm{~N}$ and total nitrogen contents (TN, wt \%) were determined on freeze-dried, ground bulk sediment of the two study sites using for Site 1239 a Carlo Erba CN analyzer 2500 interfaced directly to a Micromass Isoprime mass spectrometer at the University Bordeaux 1, and for Site 1240, a Costech 4010 elemental analyzer with a Zeroblank autosampler coupled to a Thermo Delta V isotope ratio mass spectrometer at the University of Rhode Island. Sampling resolution averages one sample every $20-30 \mathrm{~cm}(\sim 10 \mathrm{kyr})$. Precision of the isotopic analyses based on certified standard and in-house standard replicates is better than $\pm 0.3 \%$ or both machines. Typical precision for TN analysis is better than $\pm 0.02 \%$.

Some discrete samples from Site 1239 were also selected all along the record and measured for their total organic carbon (TOC, wt \%) contents at the University Bordeaux 1 using 


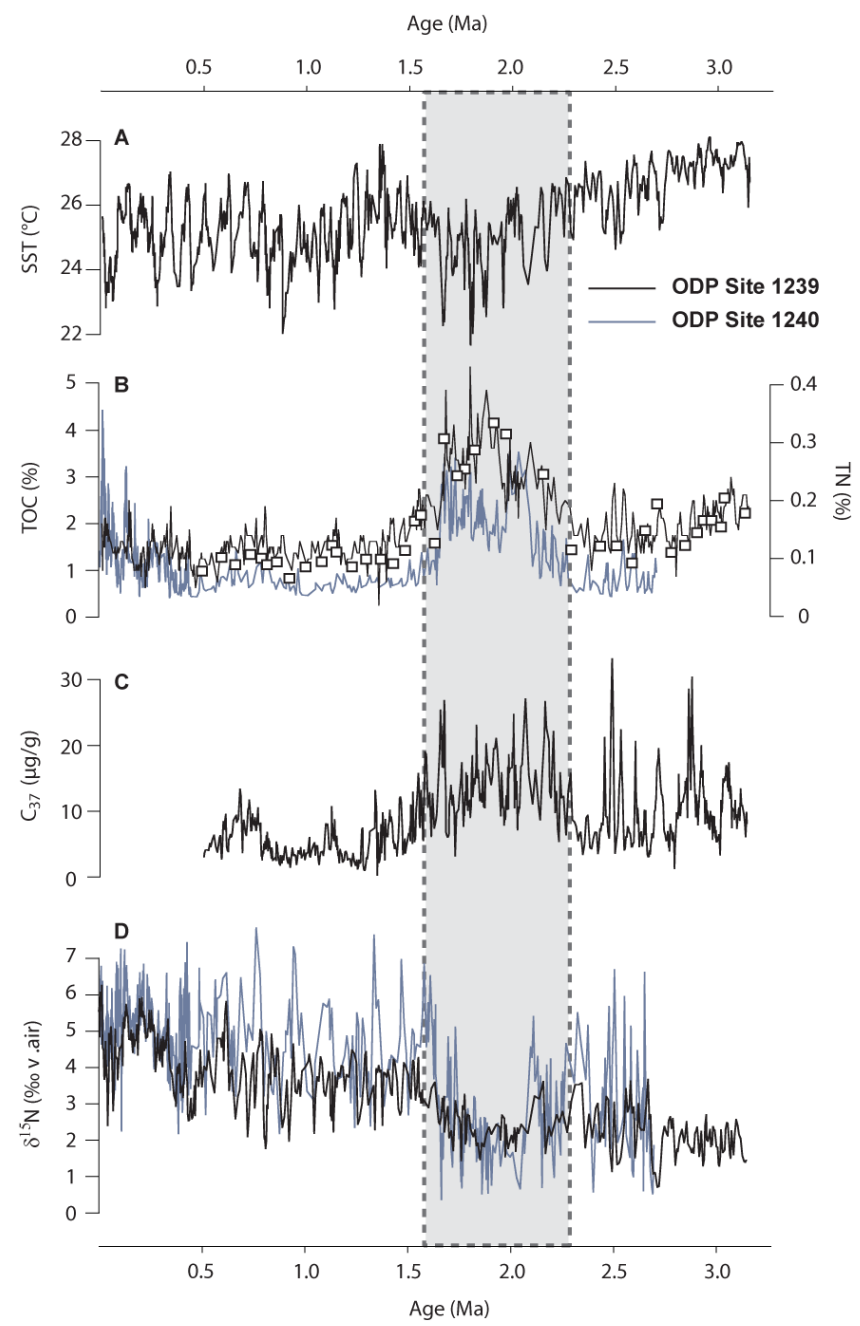

Fig. 2. Paleorecords from EEP Sites 1239 (black) and 1240 (gray). (A) Site 1239 alkenone SSTs (Etourneau et al., 2010; Rincón-Martinez et al., 2010). (B) Site 1239 TN and TOC (black square) contents (\%) and Site $1240 \mathrm{TN}$ content (\%). (C) Site $1239 \mathrm{C}_{37}\left(\mu \mathrm{gg}^{-1}\right)$. (D) $\delta^{15} \mathrm{~N}(\%$ ) records at both sites; $\delta^{15} \mathrm{~N}=\left[\left({ }^{15} \mathrm{~N} /{ }^{14} \mathrm{~N}_{\text {sample }}\right) /\left({ }^{15} \mathrm{~N} /{ }^{14} \mathrm{~N}_{\text {standard }}\right)-1\right] \times 1000 \quad$ (the standard is atmospheric $\mathrm{N}_{2}$ ). The gray shaded bar indicates the most productive period in the EEP since the Pliocene warmth.

a LECO C-S 125 analyzer after treatment of the sediment with $\mathrm{HCl}$ to remove $\mathrm{CaCO}_{3}$. The precision for TOC is better than $\pm 0.5 \%$. The alkenone concentration $\left(\mathrm{C}_{37}, \mu \mathrm{g} \mathrm{g}^{-1}\right)$ was determined at the University of Kiel at a resolution of $\sim 2-$ $4 \mathrm{kyr}$ between 3.2 and $0.5 \mathrm{Myr}$, at the same time as the $U_{37}^{k^{\prime}}$ from Site 1239 (Etourneau et al., 2010) with a precision of about $\pm 0.05 U_{37}^{k^{\prime}}$ units.

Evolutionary spectra, or temporal changes in amplitude of signal components in the Milankovitch band, over the last 3.2 Myr were estimated using TIMEFRQ 4.3 (Schulz et al., 1999). Data were prewhitened to a $2 \mathrm{kyr}$ resolution. To determine time-dependent amplitude estimates, the input time series is analyzed within a window-width factor of 3.0. Each window segment is linearly detrended prior to tapering with a Welch window.

\section{Results}

$\mathrm{TN}$ and TOC contents recorded a peak from 2.2 to $1.6 \mathrm{Myr}$ with values up to 0.4 and $4.0 \%$, respectively (Fig. 2 b). $\mathrm{C}_{37}$ concentration at Site 1239 also shows a sustained interval of high alkenone production that corresponds to the peak in TOC and TN, with maximum values of $20 \mu \mathrm{g} \mathrm{g}^{-1}$ (Fig. 2c). Intermittently, high values of $\mathrm{C}_{37}$ concentration occur prior to $2.2 \mathrm{Myr}$, while after $1.6 \mathrm{Myr}$, values are generally lower.

During the last $3.2 \mathrm{Myr}$, while the bulk sedimentary $\delta^{15} \mathrm{~N}$ record at Site 1240 displayed a higher volatility than at Site 1239 , the two records presented the lowest and nearly invariable values of $\sim 2 \%$ o during the interval of sustained elevated biogenic contents (Fig. 2d). Prior to $2.2 \mathrm{Myr}$, the $\delta^{15} \mathrm{~N}$ values oscillated between 1 and $3 \%$ at Site 1239 and from 1 to $5 \%$ o at Site 1240. In contrast, the isotopic values terminated with a strong shift of $2-4 \%$ at $1.6 \mathrm{Myr}$ towards increasing values of $\sim 5.0-6.0$ and $\sim 6.0-8.0 \%$ at Sites 1239 and 1240, respectively, during the mid- to late Pleistocene.

Between 2.7 and $1.5 \mathrm{Ma}$, the $\mathrm{C}_{37}$ and $\mathrm{TN}$ records varied at an obliquity, or $41 \mathrm{kyr}$, frequency (Fig. 3c and d). Comparatively, the late Pleistocene was characterized by the absence of any detectable frequency in these records, while the $\delta^{15} \mathrm{~N}$ record oscillated at both a $41 \mathrm{kyr}$ and eccentricity, or $100 \mathrm{kyr}$, cycles (Fig. 3b). The SST record was mainly imprinted by the 100 kyr signal through the Pleistocene, and to a lesser extent by the $41 \mathrm{kyr}$ oscillations, more dominant during the late Pliocene/early Pleistocene cooling (Fig. 3a).

\section{Discussion}

\subsection{Export production in the EEP}

The export production records from both study sites are consistent with the previously reported maximum event between 2.2 and 1.6 Myr in the eastern Pacific (Cortese et al., 2004; Dekens et al., 2007; Lawrence et al., 2006; Mix et al., 1995). This regional agreement between records is supported by the excellent correlation in terms of trend and amplitude between our alkenone concentration records and that at Site 846, located southwest of Site 1239, in the center of the equatorial upwelling system (Lawrence et al., 2006) (Fig. 4).

TN and TOC represent the overall phytoplankton production, while $\mathrm{C}_{37}$ concentration reflects changes in alkenone producers, most probably Reticulofenestra species (Bolton et al., 2011). Changes in preservation, dilution, and concentration might affect the paleoproductivity signal traced by the different proxies. The mass accumulation rate (MAR) of sediment constituent is commonly applied to estimate past export productivity fluxes. However, although the age model at our EEP sites is well constrained, the use of MAR instead 


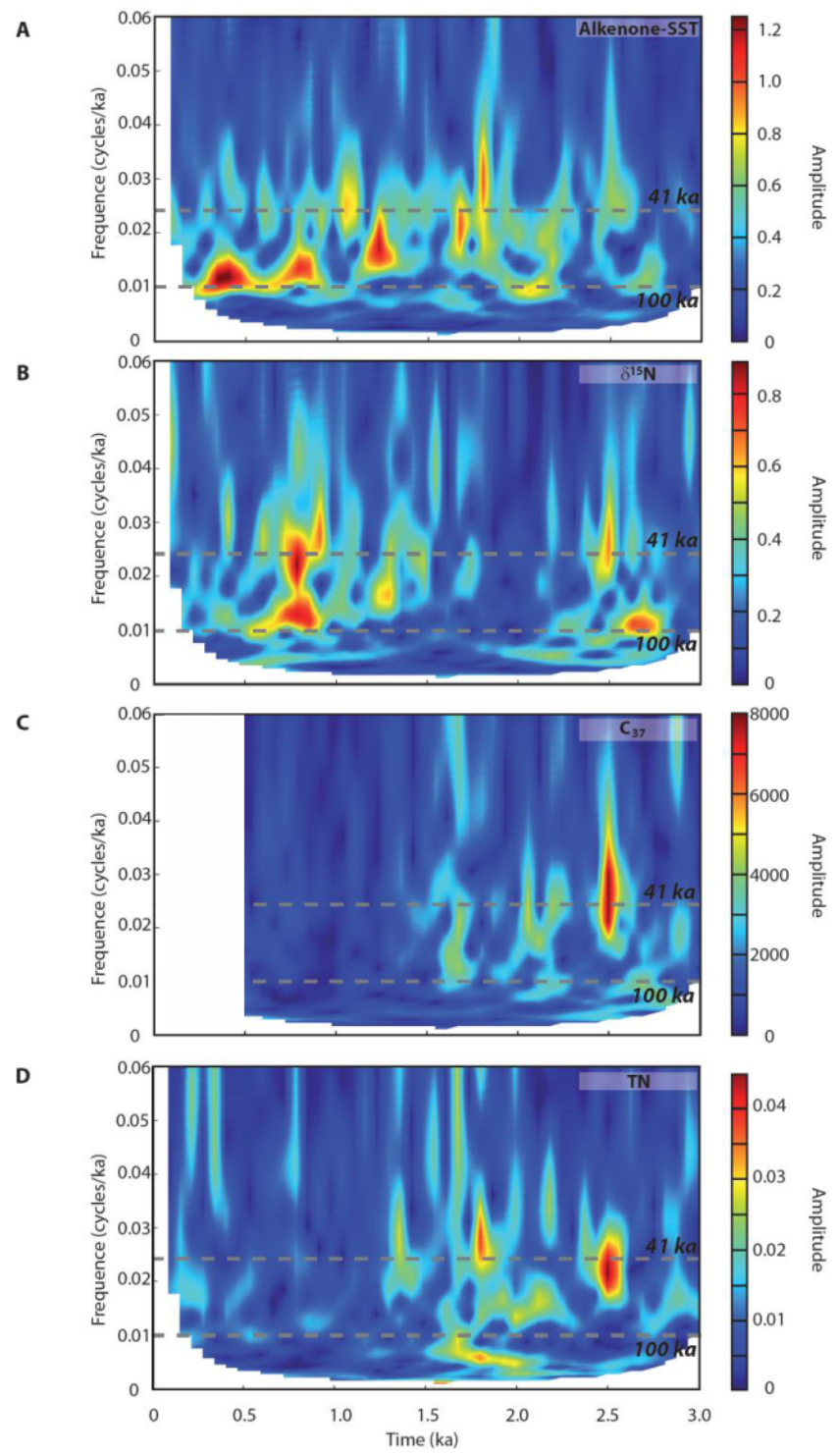

Fig. 3. Evolutionary spectra of (A) alkenone SSTs, (B) $\delta^{15} \mathrm{~N}$, (C) $\mathrm{C}_{37}$, and (D) TN at Site 1239 during the Plio-Pleistocene climate transition.

of content can be largely uncertain regarding the export productivity produced in the subsurface waters (François et al., 2004). In addition, the carbonate $\left(\mathrm{CaCO}_{3}\right)$ content has not varied significantly since 3.0 Myr (Mix et al., 2003), implying that changes in dilution or concentration of the other more minor biogenic components by carbonate fluctuations are not driving the fluctuations of the records. The exception may be during the high $\mathrm{TOC} / \mathrm{TN} / \mathrm{C}_{37}$ interval, where $\mathrm{CaCO}_{3}$ content decreases slightly (Mix et al., 2003). This probably represents a decrease in $\mathrm{CaCO}_{3}$ preservation due to high TOC delivery, but it was relatively minor compared to the high productivity-related concentrations peak centered between 2.2 and 1.6 Myr. Therefore, preservation effects unlikely played a significant role on controlling the paleopro- ductivity signal. This is further supported by similar variations in export productivity reconstructed at all EEP sites (e.g., Dekens et al., 2007; Lawrence et al., 2006). In addition, a recent work based on paleoproductivity reconstructions in this region spanning the same time interval reported consistent variations between the $\mathrm{C}_{37}$ concentration and independent floral data (Bolton et al., 2011).

We also exclude that our export production records might be influenced by any tectonic events over this time period, the main closure of the Panama gateway and the narrowing of the Indonesian seaway occurring much earlier, $\sim 4.2$ and 3.2 Ma ago, respectively (Haug et al., 2001; Karas et al., 2009). In addition, the paleoposition of the two ODP Sites 1239 and 1240 has changed negligibly over the last $\sim 4.0 \mathrm{Ma}$ with respect to oceanographic position (Gripp and Gordon, 1990; Pisias et al., 1995; Mix et al., 2003). Therefore, our records at both EEP sites must reflect the regional export production variability related to changes in regional oceanic conditions and nutrient supply during the Plio-Pleistocene climate transition.

\subsection{Nutrient and upwelling control on EEP export production}

Export production in the EEP is governed by macro- and micronutrient availability, which in turn are controlled by atmospheric and oceanic conditions (Brzezinski et al., 2011). Regional upwelling intensity plays an important role in regulating export production as it controls the nutrient supply to the photic zone.

Sedimentary $\delta^{15} \mathrm{~N}$ values provide integrated information about regional nutrient (mostly nitrate) dynamics in the EEP (e.g., Dubois et al., 2011; Dubois and Kienast, 2011; Farrell et al., 1995; Martinez and Robinson, 2010; Robinson et al., 2009). During microbial transformations, including the uptake and assimilation of nitrate as well as bacterial denitrification, ${ }^{14} \mathrm{~N}$-bearing nitrate reacts faster so that the remaining nitrate pool becomes enriched in ${ }^{15} \mathrm{~N}$-bearing nitrate (Altabet and François, 1994). In a nitrate-replete system like the EEP, the $\delta^{15} \mathrm{~N}$ of the organic matter reflects the $\delta^{15} \mathrm{~N}$ of the nitrate pool in the surface ocean. This is a combined signal that includes the $\delta^{15} \mathrm{~N}$ of the upwelled nitrate and the relative nutrient utilization of the nitrate pool at the surface.

The $\delta^{15} \mathrm{~N}$ of subsurface nitrate in the EEP can reflect the isotopic signature of preformed nitrate coming from the Antarctic and North Pacific waters that supplies most of the new nitrate delivered to the EEP through the EUC waters (Rodgers et al., 2003; Rafter et al., 2012). The influence of preformed changes is not apparent on glacial-interglacial scales (Dubois et al., 2011; Robinson et al., 2009), or on longer timescales (Billups et al., 2013; Etourneau et al., 2009; Giuliani et al., 2011). Low isotopic values have been recently documented in the Southern Ocean at $\sim 1.9 \mathrm{Myr}$ (Billups et al., 2013), during the export production maximum event, and may have had an influence on the EEP records. 


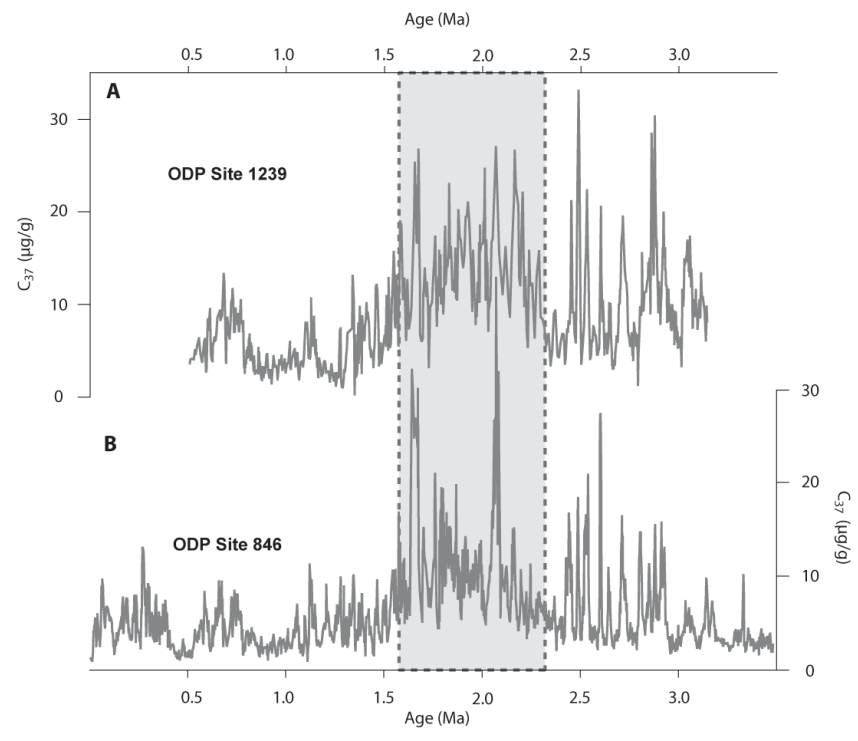

Fig. 4. Comparison of the $\mathrm{C}_{37}\left(\mu \mathrm{g} \mathrm{g}^{-1}\right)$ records at Sites 1239 (A) and 846 (B).

However, the coeval changes in $\delta^{15} \mathrm{~N}$, SST and paleoproductivity data at this time suggest rather a close connection between nutrient cycling, export production and oceanic conditions, thus not supporting the preformed signature as a strong influential factor on our $\delta^{15} \mathrm{~N}$ records.

The cycling of nitrate through the eastern tropical Pacific suboxic zone appears to impart the dominant control on the $\delta^{15} \mathrm{~N}$ of nitrate in the EEP through the SEC and NECC waters (Rafter et al., 2012; Robinson et al., 2009). The subsurface oxygen minimum zones (OMZs) in both the eastern tropical north and south Pacific are intense enough to house active zones of denitrification, which raise the $\delta^{15} \mathrm{~N}$ of subsurface nitrate significantly above the oceanic mean $(\sim 5 \%$ o) (Sigman et al., 1997). This signal is transported westward in the subsurface and upwelled to the surface, carrying the elevated nitrogen isotopic signature of denitrification into the phytoplankton pool and ultimately into the sedimentary $\delta^{15} \mathrm{~N}$ signal. Variability in bulk $\delta^{15} \mathrm{~N}$ in sediments underlying the Pacific OMZs and downstream from them, including the EEP, is largely driven by changes in the extent or intensity of denitrification (Dubois et al., 2011; Galbraith et al., 2008; Robinson et al., 2009; Martinez et al., 2006).

A shift of similar amplitude is present in the $\delta^{15} \mathrm{~N}$ record at Sites 1012, off California, at $\sim 2.1 \mathrm{Myr}$ (Liu et al., 2008), and 1242, off Costa Rica, at $\sim 1.8 \mathrm{Myr}$ (Robinson et al., submitted). The records from both margins are interpreted as a result of increasing regional denitrification (Liu et al., 2008). Changes in denitrification intensity and/or extent might have therefore strongly influenced our $\delta^{15} \mathrm{~N}$ EEP records. The same subsurface water mass bathes the EEP sites, suggesting that the increase in denitrification observed between 2.1 and $1.8 \mathrm{Myr}$ may have impacted these sites. However, the lowest $\delta^{15} \mathrm{~N}$ values correspond to the onset of the export production peak that could not be due to a transported denitrification signal, but instead to low degrees of nutrient consumption or high degrees of nutrient supply.

Given the increased demand for nutrients suggested by the high export production, nutrient supply must have been significantly enhanced. Greater nutrient supply, including nitrate and likely other nutrients (e.g., phosphorus), may reflect a change in the quantity of nutrient of the water being upwelled or simply mirror the strength of upwelling. The first situation is consistent with previous observations of a strong $41 \mathrm{kyr}$ signal in the eastern Pacific productivity and SST records (Lawrence et al., 2006; Liu et al., 2008), illustrating an emerging high latitude signal (Southern Ocean and North Pacific) where the nutrients are sourced. This is further supported by the strong obliquity frequency detected in our paleoproductivity, SST and $\delta^{15} \mathrm{~N}$ records, confirming an increasing high latitude control on EEP conditions during the late Pliocene/early Pleistocene cooling (Fig. 3a and b).

Prior to the event, between 3.2 and $2.2 \mathrm{Myr}$, export production was overall low while $\delta^{15} \mathrm{~N}$ values were relatively high and variable, indicating that nutrient supply was relatively weak, or at least much lower than during the high export production peak. Foraminiferal stable isotope and SST records from $\mathrm{Mg} / \mathrm{Ca}$ suggest a deepening of the thermocline north and south of the Equator between 3.2 and 2.2 Myr (Steph et al., 2009), implying a narrow equatorial cold tongue and a shift of the EF to the south of Equator. The export production and isotope data at our study sites are consistent with low nutrient supply such as what might occur if they were beneath or to the north of the EF, under the nutrient-poor NECC's influence.

In contrast, the $2.2-1.6 \mathrm{Myr}$ export production event cooccurred with the lowest $\delta^{15} \mathrm{~N}$ values and SSTs (Fig. 2a) (Etourneau et al., 2010; this study) suggesting a close link between sea surface water conditions and primary production. This paints a picture of an expanded cold tongue with high nitrate and other nutrient content. Furthermore, the gradient in $\delta^{15} \mathrm{~N}$ values between Sites 1239 and 1240, which is apparent before and after the high production event, collapses. This indicates that the EF sat well to the north of its present position, and the two sites were overlain by the nitrate-rich cold tongue, which is consistent with foraminifera data reconstructions (Steph et al., 2009). The intensification of the EEP upwelling is probably linked to the shoaling of the thermocline, the development of a strong zonal and meridional SST gradient in tropical/subtropical regions, which may have enhanced atmospheric circulation and divergent upwelling along the Equator, and brought the nutrient-rich polar water masses escaping the poorly used nutrient pool of the Southern Ocean and North Pacific within reach of the upwelling circulation (Billups et al., 2013; Etourneau et al., 2010; März et al., 2013).

Export production and nutrient supply decrease together at $1.6 \mathrm{Myr}$, despite strong wind-driven upwelling based upon a large west-east equatorial SST gradient (Etourneau et al., 
2010). This is likely a result of reduced nutrient contents from the high latitude source region (Etourneau et al., 2012; Cortese et al., 2004) and/or increased denitrification regionally (Liu et al., 2008). The latter mechanism stems from a potential feedback between denitrification and productivity where a decrease in regional nutrient (i.e., nitrate) availability occurs with enhanced denitrification, as it is a major sink of bio-available nitrogen. Since significant denitrification might have developed nearly at the same time as the termination of the high export production event, $\sim 2.1-1.8 \mathrm{Myr}$ ago (Liu et al., 2008; Robinson et al., 2013), it seems that the increase in denitrification engendered by the expansion of the eastern Pacific OMZs might have had a significant impact on nutrient availability and primary production in the EEP at a millionyear timescale.

On the other hand, the reduced nutrient leakage from polar regions, the main providers of new nutrient in the EEP, may be related to the observed coeval increase in export production and nutrient utilization in the Southern Ocean (Billups et al., 2013; Giuliani et al., 2011; Hillenbrand and Cortese, 2006). Increasing Fe availability in the Southern Ocean (Martinez-Garcia et al., 2011) may also have sustained high productivity in this region and therefore may have played a role in controlling nutrient consumption in polar areas. Enhanced primary productivity, hypothetically related to enhanced dust delivery to the Fe-limited polar ocean, would have greatly affected the nutrient pool in the Southern Ocean, cutting off nutrient supply via the mode and intermediate waters reaching the EUC waters. This would have thus limited export production in the EEP despite a strong supply of cold and nutrient-depleted upwelled waters.

In parallel, although not investigated here, regional changes in other nutrients' supply (e.g., Fe, phosphorus, silicic acid) may also have played a significant role in setting the productivity baseline through changes in upwelling intensity and continental supply (riverine and aeolian transport). For instance, Fe supply might have partly regulated the EEP export production, in a similar manner as recently reported for the last 1.0 Myr (Murray et al., 2012). This might be particularly true as the reorganization of the tropical/subtropical atmospheric circulation in the Pacific might have drastically altered climate conditions on continents. The Plio-Pleistocene transition in atmospheric conditions might have specifically affected continental weathering through decreasing (increasing) precipitation in the eastern (western) tropical Pacific during the establishment of a modern-like atmospheric pattern, thus regulating nutrient transport into the surface ocean. Phosphorus, an essential nutrient for phytoplankton productivity growth and ecosystem structures (Filipelli et al., 2007; Flores et al., 2012), is mostly supplied by continental erosion. It might have been widely distributed into the EEP through upwelled waters during the high export productivity peak and hence sustained biological production, as reported along the California and Peru margins (Dekens et al., 2007). In turn, the progressive depletion of the marine phosphorus pool due to changes on continental weathering could have significantly contributed to lower net production, by altering the $\mathrm{N}$ : $\mathrm{P}$ ratio and thus participated in the primary productivity decline. Moreover, the export productivity decline might be closely tied to a reduction of silicic acid supply into the EEP, likely diminishing along with the concomitant increase in biological production in the polar oceans (Billups et al., 2013; Giuliani et al., 2011; Hillenbrand and Cortese, 2006) and, in addition to the previous nutrient cited, may have accelerated the biological production collapse. However, such information with respect to the other nutrients is still missing and remains speculative, while further investigations are absolutely needed.

\section{Summary and implications}

In this study, we combine SST, paleoproductivity and nitrogen isotope records from the EEP Sites 1239 and 1240 spanning the last 3.2 Myr. We demonstrate that the largest export production event $(\sim 2.2-1.6 \mathrm{Myr})$ occurring in this region since the Pliocene warmth is inferred to be the nutrient leakage from the poorly used nutrient pool of the Southern Ocean and North Pacific to the EEP photic zone (Etourneau et al., 2012). The transport of nutrient-rich polar water masses to the EEP subsurface waters was probably amplified by the intensification of the regional upwelling driven by the development of strong atmospheric circulation in the tropical belt (Etourneau et al., 2010). Despite a strong equatorial upwelling activity maintained through the Pleistocene, polar waters upwelled in the EEP became depleted in nutrients in response to the increasing primary production in the Southern Ocean (Billups et al. 2013; Giuliani et al., 2011; Hillenbrand and Cortese, 2006). In addition, increasing denitrification in the equatorial Pacific regions (Liu et al., 2008; Robinson et al., 2013), also intimately coupled to polar oceans conditions, might have contributed to the nutrient limitation in the EEP surface waters, thereby participating additionally in the termination of the high EEP biological production event. We conclude that changes in the polar ocean climate have therefore dominantly conditioned biological production changes in the EEP over the last 5.3 Myr. However, specific studies on other nutrients are required in order to investigate all factors contributing to changes in EEP export productivity.

Acknowledgements. We acknowledge T. Blanz, I. Billy, S. Koch, and K. Charlier for geochemical and isotopic analyses and IODP for providing the samples. This research was supported by the Deutsche Forschungsgemeinschaft through German projects SCHN 621/5-2 and SCHN 621/12-1 (University of Kiel), the French program CNRS-ECLIPSE to PhM (University of Bordeaux I), the American USSSAC post-cruise support and NSF funding (1060779) to R. S. Robinson. 
Edited by: W. Kiessling

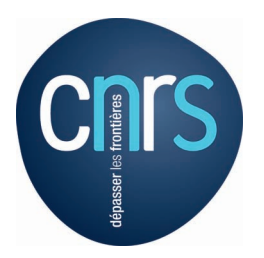

The publication of this article is financed by CNRS-INSU.

\section{References}

Altabet, M. A. and Francois, R.: Sedimentary nitrogen isotopic ratio as a recorder for surface nitrate utilization, Global Biogeochem. Cy., 8, 103-116, 1994.

Billups, K., Aufdenkampe, A., and Hays, R.: Late Miocene through early Pleistocene nutrient utilization and export production in the Antarctic Zone of the Southern Ocean, Global Planet. Change, 100, 353-361, 2013.

Bolton, C. T., Gibbs, S. J., and Wilson, P. A.: Evolution of nutricline dynamics in the equatorial Pacific during the late Pliocene, Paleoceanography, 25, PA1207, doi:10.1029/2009PA001821, 2010.

Bolton, C. T., Lawrence, K. T., Gibbs, S. J., Wilson, P. A., Cleaveland, L. C., and Herbert, T.: Glacial-interglacial productivity changes recorded by alkenones and microfossils in late Pliocene eastern equatorial Pacific and Atlantic upwelling zones, Earth Planet. Sci. Lett., 295, 401-411, 2011.

Brzezinski, M. A., Baines, S. B., Balch, W. M., Beucher, C. P., Chai, F., Dugdale, R. C., Krause, J. W., Landry, M. R., Marchi, A., Measures, C. I., Nelson, D. M., Parker, A. E., Poulton, A., Seplph, K. E., Strutton, P. G., Taylor, A. G., and Twining B.: Colimitation of diatoms by iron and silicic acid in the equatorial Pacific, Deep-Sea Res. II, 58, 493-511, 2011.

Cortese, G., Gersonde, R., Hillenbrand, C.-L., and Kuhn, G.: Opal sedimentation shifts in the world over the last $15 \mathrm{Myr}$, Earth Planet. Sci. Lett., 224, 509-527, doi:10.1016/j.eps1.2004.05.035, 2004.

Dekens, P. S., Ravelo, A. C., and McCarthy, M. D.: Warm upwelling regions in the Pliocene warm period, Paleoceanography, 22, doi:10.1029/2006PA001394, 2007.

Dubois, C. and Kienast, M.: Spatial reorganization in the equatorial divergence in the Eastern Tropical Pacific during the last $150 \mathrm{kyr}$, Geophys. Res. Lett., 38, doi:10.1029/2011GL048325, 2011.

Dubois, C., Kienast, M., Kienast, S., Normandeau, C., Calvert, S. E., Herbert, T. D., and Mix, A.: Millenial-scale variations in hydrography and biogeochemistry in the Eastern Equatorial Pacific over the last 100 kyr, Quarter. Sci. Rev., 30, 210-223, 2011.

Dugdale, R. C., Lyle, M., Wilkerson, F. P., Chai, F., Barber, T., and Peng, T. H.: Influence of equatorial diatom processes on $\mathrm{Si}$ deposition and atmospheric $\mathrm{CO}_{2}$ cycles at glacial/interglacial timescales, Paleoceanography, 19, 233, doi:10.1029/2003PA000929, 2004.

Etourneau, J., Martinez, P., Blanz, T., and Schneider, R.: PliocenePleistocene variability of upwelling activity, productivity, and nutrient cycling in the Benguela region, Geology, 37, 871-874, 2009.

Etourneau, J., Schneider, R., Blanz, T., and Martinez, P.: Intensification of the Walker and Hadley atmospheric circulations during the Pliocene-Pleistocene climate transition, Earth Planet. Sci. Lett., 297, 103-110, 2010.
Etourneau, J., Ehlert, C., Frank, M., Martinez, P., and Schneider, R.: Contribution of changes in opal productivity and nutrient distribution in the coastal upwelling systems to late Pliocene/early Pleistocene cooling, Climat. Past, 8, 1435-1445, 2012.

Farrell, J. W., Pedersen, T. F., Calvert, S. E., and Nielsen, B.: Glacial-interglacial changes in nutrient utilization in the equatorial Pacific Ocean, Nature, 377, 514-517, 1995.

Filippelli, G. M., Latimer, J. C., Murray, R. W., and Flores, J. A.: Productivity records from the Southern Ocean and the equatorial Pacific Ocean: Testing the Glacial Shelf- Nutrient Hypothesis, Deep Sea Res. II, 54/21-22, 2443-2452, 2007.

Flores, J. A., Filippelli, G. M., Sierro, F., and Latimer, J.: The "White Ocean" Hypothesis: A late Pleistocene Southern Ocean governed by Coccolithophores and driven by phosphorus, Front. Aquat. Microbiol., 3, PA3011, doi:10.3389/fmicb.2012.00233, 2012.

François, R., Frank, M., Rutgers van der Loeff, M. M., and Bacon, M. P.: $230^{T h}$ normalization: an essential tool for interpreting sedimentary fluxes during the late Quaternary, Paleoceanography, 19, PA1018, doi:10.1029/2003PA000939, 2004.

Galbraith, E. D., Kienast, M., Jaccard, S. L., Pedersen, T. F., Brunelle, B. G., Sigman, D. M., and Kiefer T.: Consistent relationship between global climate and surface nitrate utilization in the western subarctic Pacific throughout the last $500 \mathrm{ka}$, Paleoceanography, 23, PA2212, doi:10.1029/2007PA001518, 2008.

Giuliani, S., Capotondi, L., Maffioli, P., Langone, L., Giglio, F., Yam, R., Frignani, M., and Ravaioli, M.: Paleoenvironmental changes in the Pacific sector of the Southern Ocean (Antarctica) during the past 2.6 Ma, Global Planet. Change, 77, 34-48, 2011.

Gripp, A. E. and Gordon, R. G.: Current plate velocities relative to the hotspots incorporating the NUVEL-1 global plate motion model, Geophys. Res. Lett., 17, 1109-1112, 1990.

Haug, G. H., Tiedemann, R., Zahn, R., and Ravelo, A. C.: Role of Panama uplift on oceanic freshwater balance, Geology, 29, 207210, 2001.

Hillenbrand, C.-D. and Cortese, G.: Polar stratification: A critical view from the Southern Ocean, Palaeogeog., Palaeoclim., Palaeoecol., 242, 240-252, 2006.

Karas, C., Nürnberg, D., Gupta, A. K., Tiedemann, R., Mohan, K., and Bickert, T.: Mid Pliocene climate change amplified by a switch in Indonesian subsurface throughflow, Nature Geosci., 2, 434-438, doi:10.1038/NGE520, 2009.

Kessler, W. S.: The circulation of the eastern tropical Pacific, A review, Prog. Oceanogr., 69, 181-217, 2006.

Kienast, M., Kienast, S. S., Calvert, S. E., Eglinton, T. I., Mollenhauer, G., François, R., and Mix, A.: Eastern Pacific cooling and Atlantic overturning circulation during the last deglaciation, Nature, 443, 846-849, 2006.

Lawrence, K. T., Liu, Z., and Herbert, T. D.: Evolution of the eastern tropical Pacific through Plio-Pleistocene glaciation, Science, 312, 79-83, doi:10.1126/science.1120395, 2006.

Levitus, S. and Boyer, T. P.: World Ocean Atlas 1994,World Ocean Atlas 1994: Volume 4: Temperature. NOAA Atlas NESDIS. US Government Printing Office: Washington, DC, 1994.

Lisiecki, L. E. and Raymo, M. E.: A Pliocene-Pleistocene stack of 57 globally distributed benthic $\delta^{18} \mathrm{O}$ records, Paleoceanography, 20, PA1003, doi:10.1029/2004PA001071, 2005.

Liu, Z., Altabet, M. A., and Herbert, T. D.: Plio-Pleistocene denitrification in the eastern tropical North Pacific: Intensifi- 
cation at 2.1 Ma, Geochem. Geophys. Geosys., 9, Q11006, doi:10.1029/2008GC002044, 2008.

Loubere, P.: Marine control of biological production in the eastern equatorial Pacific, Nature, 406, 497-500, 2000.

Martinez, P. and Robinson, R. S.: Increase in water column denitrification during the last deglaciation: the influence of oxygen demand in the eastern equatorial Pacific, Biogeosciences, 7, 1-9, doi:10.5194/bg-7-1-2010, 2010.

Martinez, P., Lamy, F., Robinson, R. S., Pichevin, L., and Billy, I.: A typical $\delta^{15} \mathrm{~N}$ variations at the southern boundary of the East Pacific oxygen minimum zone over the last $50 \mathrm{ka}$, Quart. Sci. Rev., 25, 3017-3028, 2006.

Martinez-Garcia, A., Rosell-Melé, A., Jaccard, S. L., Geibert, W., Sigman, D. S., and Haug, G. H.: Southern Ocean dust-climate coupling over the past four million years, Nature, 476, 312-316, 2011.

März, C., Schnetger, B., and Brumsack, H.-J.: Nutrient leakage from the North Pacific to the Bering Sea (IODP Site U1341) following the onset of Northern Hemispheric Glaciation, Paleoceanography, 28, 68-78, doi:10.1002/palo.20011, in press, 2013.

Mix, A. C., Tiedemann, R., and Blum, P.: Site 1239: Proceedings Ocean Drilling Program Initial Reports, 202, College Station, Tex, 2003.

Murray, R. W., Leinen, M., and Knowlton, C. W.: Links between iron input and opal deposition in the Pleistocene equatorial Pacific Ocean, Nature Geosci., 5, 270-274, doi:10.1038/NGEO1422, 2012.

Pena, L. D., Cacho, I., Ferretti, P., and Hall, M. A.: El NiñoSouthern Oscillation-like variability during glacial terminations and interlatitudinal teleconnections, Paleoceanography, 23, PA3101, doi:10.1029/2008PA001620, 2008.

Pennington, T. J., Mahoney, K. L., Kuhawara, V. S., Kolber, D. D., Calienes, R., and Chavez, F. P.: Primary production in the eastern tropical Pacific, A review, Prog. Oceanogr., 69, 285-317, 2006.

Philander, S. G. and Fedorov, A. V.: Role of tropics in changing the response to Milankovitch forcing some three million years ago, Paleoceanography, 18, PA1045, doi:10.1029/2002PA000837, 2003.

Pisias, N. G., Mayer, L. A., and Mix, A. C.: Paleoceanography of the eastern equatorial Pacific during the Neogene: synthesis of Leg 138 drilling results, Proc. Ocean Drill. Progr. Sci. Res.,138, College Station, Tex, 1995.
Rafter, P. and Charles, C. D.: Pleistocene equatorial Pacific dynamics inferred from the zonal asymmetry in sedimentary nitrogen isotopes, Paleoceanography, 27, PA3102, doi:10.1029/2012PA002367, 2012.

Rincón-Martinez, D., Lamy, F., Contreras, S., Leduc, G., Bard, E., Saukel, C., Blanz, T., Mackensen, A., and Tiedemann, R.: More humid interglacials in Ecuador during the past $500 \mathrm{kyr}$ linked to latitudinal shifts of the equatorial front and the Intertropical Convergence Zone in the eastern tropical Pacific, Paleoceanography, 25, PA2210, doi:10.1029/2009PA001868, 2010.

Robinson, R. S., Martinez, P., Pena, L. D., and Cacho, I.: Nitrogen isotopic evidence for deglacial changes in nutrient supply in the eastern equatorial Pacific, Paleoceanography, 24, PA4213, doi:10.1029/2008PA001702, 2009.

Rodgers, K. B., Blanke, B., Madec, G., Aumont, O., Ciais, P., and Dutay, J.: Extratropical sources of Equatorial Pacific upwelling in an OGCM, Geophys. Rese. Lett., 30, 1084, doi:10.1029/2002GL016003, 2003.

Sarmiento, J. L., Gruber, N., Brzezinski, M. A., and Dunne, J.: High-latitude controls of thermocline nutrients and low latitude biological productivity, Nature, 427, 56-60, 2004.

Schulz, M., Berger, W. H., Sarnthein, M., and Grootes, P. M.: Amplitude variations of 1470-year climate oscillations during the 100,000 years linked to fluctuations of continental ice mass, Geophys. Res. Lett., 26, 3385-3388, 1999.

Sigman, D. M., Altabet, M., Michener, R., McCorkle, D. C., Fry, B., and Holmes, R. M.: Natural abundance-level measurement of the nitrogen isotopic composition of oceanic nitrate: An adaptation of the ammonia diffusion method, Mar. Chem., 57, 227-242, doi:10.1016/S0304-4203(97)00009-1, 1997.

Steph, S., Tiedemann, R., Prange, M., Groeneveld, J., Schulz, M., Timmermann, A., Nürnberg, D., Rülhemann, C., Saukel, C., and Haug, G.: Early Pliocene increase in the thermohaline overturning preconditioned the development of the modern equatorial Pacific cold tongue: Paleoceanography, 25, PA2202, doi:10.1029/2008PA001645, 2009.

Toggweiler, J. R., Dixon, D., and Broecker, W .S.: The Peru upwelling and the ventilation of the South Pacific thermocline, J. Geophys. Res., 96, 20467-20497, 1991. 